\section{Making the diagnosis of asthma}

\section{Measurement of airway responsiveness should be more readily available}

EDITOR-I welcome Taylor's call for greater use of objective tests of variable airflow obstruction in patients with suspected asthma and particularly his cautious endorsement of measurement of airway responsiveness. ${ }^{1}$ I do not, however, agree with him that the relatively weak correlation between measures of the variability in peak expiratory flow and airway responsiveness (observed in community studies) confirms that these tests measure different pathophysiological aspects of asthma. A more likely explanation is that, in most situations, both tests identify a similar abnormality but that measurement of airway responsiveness does so much more successfully than serial monitoring of peak expiratory flow.

This view is supported by several studies showing that, to achieve the same level of specificity, the sensitivity of various measures of the variability in peak expiratory flow in detecting symptomatic asthma in a community population is two to four times less than that of measurement of airway responsiveness. ${ }^{2}{ }^{3}$ Furthermore, if attempts are made to increase the signal (and presumably the sensitivity) of variability in peak expiratory flow by incorporating readings obtained after use of a bronchodilator the correlation with measurement of airway responsiveness becomes close. $^{4}$

In a population in which the diagnosis of asthma is in doubt the low sensitivity of measures of variability in peak expiratory flow plus the relatively high incidence of false positive and negative results due to measurement error, poor compliance, and perhaps upper airway dysfunction ${ }^{5}$ seriously limits its diagnostic value. Is it not time Britain followed the rest of the developed world and made measurement of airway responsiveness more readily available?

Ian D Pavord Consultant physician

Glenfield Hospital, Leicester LE3 9QP

1 Taylor DR. Making the diagnosis of asthma. BMJ 1997;315:4-5. (5 July)

2 Siersted HC, Hansen HS, Hansen NG, Hyldebrandt N, Mostgaard G, Oxhoj H. Evaluation of peak expiratory flow variability in an adolescent population. Am J Respir Crit Care Med 1994;149:598-603.

3 Higgins BG, Britton JR, Chinn S, Cooper S, Burney PGJ Tattersfield AK. Comparison of bronchial reactivity and peak expiratory flow variability for epidemiologic studies. Am Rev Respir Dis 1992;145:588-93.

4 Ryan G, Latimer KM, Dolovich J, Hargreave FE. Bronchial responsiveness to histamine: relationship to diurnal variation of peak flow rate, improvement after bronchodilator and airway calibre. Thorax 1982;37:423-9.

5 Bucca C, Rolla G, Brussino L, De Rose V, Bugiani M. Are asthma-like symptoms due to bronchial or extra-thoracic asthma-like symptoms due to bronchial or
airway dysfunction? Lancet 1995;346:791-5.

\section{Trial of steroids is useful}

EDITOR-I am mystified why Taylor failed to discuss, or even mention, the objective response to corticosteroid treatment, which most clinicians now use to establish a diagnosis of asthma. ${ }^{1}$ The "steroid trial" that I and most of my colleagues use is simple, safe, and of great diagnostic help, especially in adults when the clinician is confronted by the common clinical dilemma of differentiating between asthma and chronic obstructive airways disease. Taylor correctly emphasises the value of serial measurements of peak flow in the diagnosis of asthma. $\mathrm{He}$ ignores, however, the even more important information obtained if one asks the patient to continue to record peak expiratory flow values twice daily while taking prednisolone $30 \mathrm{mg}$ or $40 \mathrm{mg}$ once daily in the mornings for 10-14 days. This, in my experience, is the most important investigation of any patient with chronic airflow obstruction.

Challenge tests with methacholine have little or no diagnostic role in clinical respiratory medicine but are used extensively by epidemiologists, who usually have great difficulty in defining the clinical relevance of positive, or even negative, results of challenge tests. Taylor refers on more than one occasion to the "bronchodilator reversibility test." His comments about the diagnostic value of such a test are vague. On balance I think he doubts the reliability of this frequently performed investigation, and if my interpretation of his views is correct he has my full agreement. It may be that Taylor is a paediatrician or epidemiologist and this is why his editorial will be little help, and indeed may create some confusion, if read by a clinician concerned primarily with adult patients with airways disease.

The steroid trial does not diagnose asthma. Nevertheless, patients with chronic airflow obstruction in whom mean peak expiratory flow improves by $\geqslant 15 \%$ during treatment with oral prednisolone should be treated as if the primary diagnosis was asthma.

G K Crompton Consultant physician

Respiratory Unit, Western General Hospital, Edinburgh EH4 2XU

1 Taylor R. Making the diagnosis of asthma. BMJ 1997; 315:4-5. (5 July.)

\section{Relation between asthma and bronchial} hyperresponsiveness is not clear cut

EDITOR-Taylor makes a valiant effort to grapple with the enduring problem of how you diagnose asthma. ${ }^{1}$ He places undue emphasis, however, on tests of non-specific bronchial hyperresponsiveness. Although at a population level bronchial hyperresponsiveness is clearly related to asthma, this relation is not so clear cut at the individual level and is influenced by definitions used for asthma and bronchial hyperresponsiveness.

At any one time only two thirds of people with asthma diagnosed on the basis of symptoms show bronchial hyperresponsiveness, while one third have no current respiratory symptoms. ${ }^{23}$ Clough et al reported a longitudinal study of 196 children assessed over 12 months. ${ }^{4}$ Bronchial responsiveness to methacholine was tested every month and varied considerably over the course of the study: a third of the children showed a variation of more than four doubling dilutions in the cumulative dose of methacholine resulting in a $20 \%$ fall in forced expiratory volume over the 12 months. Of those who were both atopic and reported wheeze, $11 \%$ did not have bronchial hyperresponsiveness at any time during the study. Specific tests of bronchial responsiveness may be superior to nonspecific tests such as methacholine. Avital et al have shown that adenosine is a better discriminator than methacholine both between asthma and absence of bronchial disease and between asthma and other causes of chronic obstructive pulmonary disease. ${ }^{5}$

Iolo Doull Consultant respiratory paediatrician University Hospital of Wales, Cardiff CF4 4XW

1 Taylor DR. Making the diagnosis of asthma. BMJ 1997;315:4-5. (5 July.)

Sears MR, Jones DT, Holdaway MD, Hewitt CJ, Flanery EM, Herbison GP, et al. Prevalence of bronchial reactivity to inhaled methacholine in New Zealand children. Thorax 1986;41:283-9.

3 Pattemore PK, Asher MI, Harrison AC, Mitchell EA, Rea $\mathrm{HH}$, Stewart AW. The inter-relationship among bronchial hyper-responsiveness, the diagnosis of asthma, and asthma hyper-responsiveness, the diagnosis of asthma, and
symptoms. Am Rev Respir Dis 1990;142:549-54.

4 Clough JB, Williams JD, Holgate ST. Effect of atopy on the natural history of symptoms, peak expiratory flow, and natural history of symptoms, peak expiratory flow, and
bronchial responsiveness in 7 and 8 year old children with bronchial responsiveness in 7 and 8 year old children with
cough and wheeze. Am Rev Respir Dis 1991;143:755-60.

5 Avital A, Springer C, Bar-Yishay E, Godfrey S. Adenosine methacholine and exercise challenges in children with asthma or paediatric chronic obstructive pulmonary disease. Thorax 1995;50:511-6.

\section{Compliance is not all}

EDITOR-Bamforth is correct in spotting the wrong preposition in the quotation from Franz Kafka. ${ }^{1}$ In the course of some enthusiastic technical editing of my article, Kafka was omitted and restored only as the result of my last minute appeal on the telephone. ${ }^{2}$ Somehow BT (the telecommunications company), my diction, and the technical editor's hearing conspired to substitute the offending preposition. Bamforth's summary of Kafka's story, however, usefully warns us of the contrast between professional empathy (a cornerstone of concordance) and uncontrolled transference (the fate of Kafka's fictional doctor). In the working party report that I referred to, the correct translation of Kafka's quotation appears, as Bamforth gives it. ${ }^{3}$

In their letter Milburn and Cochrane express three reservations about concordance. ${ }^{4}$ Firstly, they observe that drug trials demand high levels of compliance to establish effectiveness and dose. In clinical practice half of patients with chronic conditions fail to achieve this compliance. Does this mean that the results of these trials can be of help only to (an unpredictable) half of the population of patients to be treated? The singleminded pursuit of compliance may provide proof of effectiveness but seems unable to deliver reliable benefit.

Secondly, they claim that cognitive analytic psychotherapy has helped to improve patients' compliance. If as a consequence the patient is able to benefit more fully from the treatment then he or she does so as an active partner. Psychotherapy aims to empower, not control, the 